\title{
Transformational Adaptation in Agriculture under Climate Change: A Case Study in the Dry Zone of Sri Lanka
}

\author{
Lal Mervin Dharmasiri and Mangala Jayarathne \\ Senior Professor and Carder Chair, Department of Geography, University of Kelaniya, Sri Lanka and Senior Lecturer, \\ Department of Geography, University of Kelaniya, Sri Lanka
}

Received: 2021-03-02 Accepted: 2021-07-07

\section{Keywords:}

Transformational adaptation, Climate change,

Climate Smart Agriculture

Correspondent email: mervin@kln.ac.lk

\begin{abstract}
Transformational adaptation defines as 'changes the fundamental attributes of a system in response to climate and its effects.' Farmers deal with the natural environment and its components such as rainfall, temperature, humidity, and soil condition, which have a high range of variability and uncertainty for their cultivation. The present study focused on the impacts of climate change on the settler community who engage in agriculture as their mainstay and respond to the scenario. Quantitative and qualitative methods have been applied. Twenty samples from a village in the NCP have been selected. Primary outcomes of this study are (a) total awareness of perceptions on climate change; (b) the ambient temperature has been increasing and resulting in more heat stress; (c) frequent and severe occurrence of extreme rainfall anomalies and increasing trend of natural calamities. The area farmers have been adopting several strategies to overcome the negative impacts of climate change, such as transforming from intensification to more intensification that can be identified as Climate Smart Agriculture; crop diversification and adaptation of drought tolerance crops; transforming from agriculture to animal husbandry, and out-migration of unemployed or evicted youth from agriculture to non-agriculture. Institutional involvement is essential to strengthening the adaptative strategies of the people by providing an appropriate crop calendar and suitable crop combination and aware of the way of improving the use of the efficiency of available water for improving the living standard of the people.
\end{abstract}

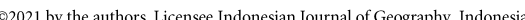

This article is an open access article distributed under the terms and conditions of the Creative Commons

This article is an open access article distributed under the terms and conditions of
Attribution(CC BY NC) licensehttps://creativecommons.org/licenses/by-nc/4.0/.

\section{Introduction}

This study has three terminologies, i.e., Transformation, Agriculture under Climate change, and Climate change adaptation. Climate Change is a long-term shift in the climate of a specific location, region, or planet. The shift is measured by changes in features associated with average weather, such as temperature, rainfall, wind patterns, and precipitation. 'Climate Change' is the biggest emerging environmental challenge to date (Anu Adhikari et al., 2011). 'Transformational climate change adaptation' in agriculture as major, purposeful action undertaken at the farm or suprafarm level in response to potential or actual climate change impacts and opportunities in the context of other drivers (Rickards and Howden, 2012). Moser and Ekstrom (2010) stated that the adaptation involves changes in socialecological systems in response to actual and expected impacts of climate change in the context of interacting non-climatic changes.

The IUCN defines (2011) 'adjustment' in natural or human systems to a new or changing environment is known as adaptation. Adaptation is a continuous process by which individuals, communities, and countries seek to cope with the consequences of climate change. It is possible to categorize different types of adaptation, including anticipatory and reactive adaptation, private and public adaptation, and autonomous and planned adaptation. Adapting to climate change has been widely discussed in adaptation literature during the last couple of years by climate change specialists in the World. It has been further distinguished into 'incremental' and 'transformational' adaptation (IPCC, 2001). According to the CASP report, incremental adaptation refers to an action where the central aim is to maintain the essence and integrity of a system or process at a given scale". Transformational adaptation defines as a "changes the fundamental attributes of a system in response to climate and its effects." In general, incrementally adaptation involves using familiar strategies and measures to overcome losses, damage, or increase the production/ yield associated with climate change. Transformational adaptation is predicated on recognizing that existing systems and practices may be unsuitable under emerging capacity and marginal returns from farm activities related to climate change. For example, they are shifting from rice cultivation to cash crop production due to decreasing yield and water scarcity.

It may be an essential change to, or replacement, or alternative of, existing system and practices. The transformational adaptation further can be broadly categorized into five types (See; Maria and Mike, 2018).

a. Adaptation actions adopted at a larger scale;

b. Shifting and changing agricultural systems;

c. Changing business scale, structure, and location;

d. Creating new croplands/irrigation; and

e. Forced farm abandonment and migration. 
Transformational adaptation may be driven as a vital requirement in climate change that results in failure of the existing system and unviable farming activities. There is no option other than by adopting a new system and alternative strategies to overcome the constraints. The literature provided here would be useful to identify the adaptation system and good activities which can be transmitted to other sets of farmers.

The population of Sri Lanka is about 21.4 million and is predicted to reach over 21.81 million by 2050 and increase the demand for foodstuffs. The required foodstuff, including cereal, vegetables, fruits, animal products, oils, and other edible things, places more pressure ever on the agricultural system to increase production. Simultaneously cultivable land, water availability, soil quality, and favorable climatic conditions have been changing day by day. Guarino and Lobell (2011) stated that climate change is a serious threat to increasing people's food demand. This widening mismatch between demand and supply is causing grave concern for future food security (Hannes et al., 2014).

Farmers deal with the natural environment and its components such as soil, water, temperature, and sunshine. Most of these components come under weather conditions, which have a high range of variability and uncertainty. Since the farmer doesn't have a controlling capacity to maintain favorable conditions for farming, they create substantial challenges. Small-scale farmers who have a tiny plot of land for cultivation face this challenge and are more vulnerable to natural calamities.

By 2050, much of the World will experience a growing season that will likely have higher temperatures than the hottest growing seasons of recent times, and this increase in temperatures will probably be accompanied by more variable rainfall (Battisti and Naylor, 2009). Crops yield will be impacted in various ways due to climate change. Loss of cultivation, water scarcity, land degradation, speeding pest, and fungus may be the most significant threats in the future. In 2019, The United States Environmental Protection Agency (EPA) pointed out that climate change can disrupt food availability, reduce access to food, and affect food quality. When increases in temperatures, changes in precipitation patterns, changes in extreme weather events, and reductions in water availability may all result in reduced agricultural productivity, adding up these and other effects, models show possible yield losses of $6-10 \%$ per $1{ }^{\circ} \mathrm{C}$ of warming in the average temperature of the growing season (Guarino and Lobell 2011).

Different scholars of Sri Lanka had done several studies, which are related to climate change scenarios. Fernando (2000) has studied the impacts of climate change on paddy production in Sri Lanka. In addition, Dharmasiri (2013) has examined the possibility of applying crop diversity for managing issues of water-related problems in the Mahaweli system in Sri Lanka. Panabokke and Punyawardena (2010) also identified how climate change impacts rain-fed agriculture in the Dry zone of Sri Lanka. Jayawardene et al. (2005) had done a study to determine the rainfall variability in Sri Lanka. The study was based on more recent data records (1949 onwards), revealing a decreasing trend in 13 of the 15 stations of the country. Thus, traces of a temporal change seem to be apparent in the rainfall records over the last half-century. De Costa (2008) and Marabe et al. (2013) identified the adverse impact of climate change on the food security of Sri Lanka Agricultural adaptation, and Esham and Garforth (2013) identified mitigation strategies with reference to the farming community in Sri Lanka. A model of the HadCM3, a coupled atmosphere-ocean general circulation model, was used to identify the impacts of climate change in the country. This model predicted that the rainfall would decrease in Dry zones areas of the country due to climate change (De Silva et al., 2007). Another study on 'Adaptation to the vulnerability of paddy cultivation to climate' was done by Chithranayana and Punyawardena (2014). It revealed a high spatial variability of the onset time of both the Yala and Maha seasons and proposed an alternative crop calendar to overcome it. Further, Gunawardhana and Dharmasiri (2013) pointed out that farm and off-farm adaptation strategies are being used by the people in the North Central Province to cope with the effects of drought due to climate change.

Transformational adaptation to climate change may be a key strategy available for facing the adverse impacts of climate change in most sectors, in particular agricultural sectors in developing countries like Sri Lanka. Accordingly, several adaptation strategies and actions may be identified at the field level (micro-level) to overcome, moderate, cope or take advantage of experienced or anticipated changes in climate.

\section{Transformational climate change adaptation}

Climate change encompasses not a rise in average temperatures but also extreme weather events, shifting wildlife population and habitats, rising seas, and a range of other impacts (National Geographic, 2020). According to Gori et al. (2018), climate change has caused changes in land use besides exerting pressure on water resources, thereby affecting ecosystems' capacity to sustain food production, ensuring an uninterrupted supply by freshwater resources supply; providing ecosystem services, and; promoting the rural multi-functionality. On the other hand, climate change is a ubiquitous phenomenon having wide-ranging social, economic, political, geographical, ecological, and psychological implications (Zakeer and Nawaz, 2020). Most of the developing countries relying on agriculture for the national economy have been facing severe problems. When most farmers are small-scale holders or subsistence, they are more vulnerable to climate change issues. Different scholars all over the World have consistently studied climate change, impacts on climate change, climate change adaptation, and farmer adaptation to climate change. The bulk of agricultural studies on the effect of climate change have focused on crops. However, a significant fraction of agricultural output is from livestock (Seo and Mendelsohn, 2008). It is necessary to look at the new strategies that the different communities have adopted on these aspects. Most agricultural studies on the effects of climate change have focused on crop cultivation, while very limited attention is given to the livestock sector. Hence, it is worth further exploring the effect of climate change on herders, focusing on how it changes the quality and habits of animals, thereby livestock productivity. As an objective of this study, the researcher focused on the impacts of climate change on the settler community who engage in agriculture as their mainstay and respond to the scenario.

The Germanwatch institute had calculated the Global Climate Risk Index (CRI) 2020 (Gremanwatch, 2020; Eckstein, 2020). Based on the analysis of the impacts of 
extreme weather events and the tangible losses they cause, Japan, which recorded a CRI of 5.5, is the most affected place by climate change today. Climate change experts have estimated that due to many people either directly or indirectly dependent on the country's economy on agriculture, Sri Lanka ranks $6^{\text {th }}$ amongst the most vulnerable countries to climate change, world-over (Noman and Schmitz, 2011). Sri Lanka's CRI is 19 and just below five countries in the World. Furthermore, weather events in 2018 caused 38 deaths in Sri Lanka - 0.18 per 100,000 inhabitants, over 3,625 million dollars in losses, and a collapse in per capita GDP of $1.24 \%$.

Under the situation that all the people should have been exposed to climate change in the World today. Some of them in the agricultural sector are heavily affected by destroying or lowering harvest, reducing farm income, and increasing absolute poverty. However, some farmers have adapted to climate change for the survival of their lives. In that respect, it is necessary to understand the magnitude of climate change and the response of the peoples to overcome the adverse impacts. Climate change adaptation is a process that could manage the adverse situation to overcome it. It differs from person to person, community to community, or country to country. Nature and the process of adaptation also differ from each other.

The Government of Sri Lanka (GoSL) prepared 'The National Adaptation Plan (NAP) for Climate Change Impacts' in 2010 and adopted it in 2012. It was prepared in line with the broad set of guidelines set forth by the UNFCCC to develop national adaptation plans (Climate Change Secretariat, 2016). It was clearly indicated the component of agriculture-related 'food security, which comes under the NAP. Accordingly, several gaps are remaining in climate change adaptation in agriculture in Sri Lanka. In particular, farmer behavior with necessary research regarding culture, ethnicity, religion, gender, and social network could be identified as gaps. Accordingly, this article aims to investigate and identify the approaches of the different communities to climate change adaptation possible to come up to poverty alleviation and enhancing their living slandered lives. Further, it focuses more specifically on the problem of numerous small-scale farming families engaged in traditional agriculture, such as paddy, who currently fail to get access to better outcomes from their cultivation due to the impacts of climate change.

\section{Problem statement}

Sri Lanka is predominantly, and the majority of the population dependent on peasant agriculture was the dominant economic activity in terms of the number of people employed. In 2019, $81.42 \%$ of countries' population lived in rural areas. Sri Lanka is a developing country, and nearly one-fourth $(25.3 \%)$ of the labor force directly depends on agriculture. The figure amount would be more than doubled when considering the indirect employment provided by the country's agricultural sector. Paddy is the single most important crop cultivated in the peasant sector, and it is grown mainly in the Dry zone of Sri Lanka, largely as subsistence cultivation. Other commercial field crops include chili, onion, vegetables, pulses, maize, and other cereals cultivated on a small scale as cash crops. Farms in the hill country also produce 'up-country vegetables', such as carrots, leeks, cabbage, and potato. Although some are grown for export, fruits and vegetables cultivate both in large scale Estates and smallholdings. Tea, rubber, and coconut are the major agricultural commodities for export. The agricultural sector of the country has earned export revenue of 1,085 USD Million in June of 2020. However, small-scale farmers contribute more than $60 \%$ of total agricultural production. The majority of the small-scale farmers have less than five acres in size (typically between 1.5 and 2.5 acres). Most of them cultivate crops under both rain-fed and irrigated conditions, mainly depending on the seasonality of the rainfall in the Dry zone areas, while the Wet zone agriculture is predominantly rain-fed. Recently, farmers in the Dry zone have been experiencing rainfall variability and unusual intensity, which have frequently been causing damage to crop cultivation. The increasing tendency of temperature is also causing severe damage to agricultural production, particularly in the Dry zone of Sri Lanka. Some farmers have understood the environmental scenario and have been practicing different techniques to overcome the situation while none of the others.

Several studies have identified that adaptation is vital to minimize climate change vulnerabilities anywhere in the World. Wijeratne (1996) has examined the vulnerability of Sri Lanka's tea production under climate change. De Silva et al. (2007) have predicted the water requirement for paddy cultivation under climate change in Sri Lanka. Another study has been done in Burkina Faso, which identified the adoption by farmers has been uneven, and some success stories have been reported (Malicki et al., 2012). The pastoral societies in Ethiopia could be identified as a different agricultural system in the World that has tried to employ their own strategies to minimize climate change-induced losses (Yilma et al., 2019). Even though there are significant kinds of literature on climate change and agricultural adaptation available, there is a lack of studies on the small-scale agricultural sector in the Dry zone of Sri Lanka. Menike and Keeragala Arachchi (2016 ) also studied the smallholder farmers in rural communities in the upcountry intermediate zone in Sri Lanka. Accordingly, the present study focuses on identifying how the small-scale farmers in the Dry zone of Sri Lanka could have been able to overcome the climate change impacts by adopting alternative strategies.

\section{Methods}

Sri Lanka is highly vulnerable to the effects of climate change, and its impacts are especially evident in the agricultural sector. Many studies have identified that the small-scale farming sector of the Dry zone has been poorly affected in terms of the deteriorating living standard of the farming community, while some were able to overcome the adverse impacts.

Change pattern of climate is to be identified with available data from the Department of Meteorology and analyzing them to identify the long-term trends in rainfall and temperature in the area. In particular, long-term average variability is measured by considering the two main agricultural seasons of Yala and Maha a year. Accordingly, 30 years of climatic data in three weather stations were located near the study area, i.e., Anuradhapura, Vauniya, and Trincomalee. The data were analyzed by considering (a) Average annual rainfall/ temperature, (b) Average Yala season rainfall/ temperature, and (c) Average season Maha season rainfall/ temperature. All the climatic data gathered 
from the Department of Climatology used to identify the climate change in the study area.

Sample village was identified to conduct a micro-level study by considering the following criteria ;

a. Village located in areas vulnerable to the effects of climate change,

b. The different cultural identities and practices of the village,

c. The different agricultural practices in the village,

d. The majority of the people are small-scale farmers of the village.

Accordingly, Diyatitta Wewa Grama Niladhari Division (hereafter DTW) at the Horwpathana Divisional Secrete (HDS) in the North Central Province (NCP) has been selected for study, where the Muslim community predominates. Muslim and Sinhala communities in Sri Lanka are exposed to very different cultural, socio-economic, and demographic experiences. They also have different strategies for combatting seasonality and climate change in the arid northern reaches of the island, including the focus on different crops and cultivation patterns.

The methodology that has been applied for this study is a mixed-method, which comprises quantitative and qualitative approaches. The sample size was 20 , selected by a random sample for the quantitative analysis. Apart from the data collected from small-scale farmers in the village, lengthy discussions were held with the Government officials and Non -governmental organizations in the area.

\section{Result and Discussion}

\section{Climate trends at the study area}

The Dry zone (Figure 1), which covers more than $70 \%$ of the total land extent in Sri Lanka, is the major agricultural region of the country and more than $60 \%$ of the people depend on it. The North Central Province (NCP) is the largest and highest number of people dependent on agriculture among the other zones of the Northern Provinces. The NCP consists of two districts, i.e., Anuradhapura and Polonnaruwa Districts and 30 Divisional
Secretariat (DS) in Sri Lanka and the Horowpothana DS (HDS) located within the Anuradhapura District. The HDS has 38 Grama Niladhari (GN) divisions which cover 845.81 square $\mathrm{km}$ and live 13,015 householders within the area. For this study, available data from the three substations of the Meteorological Department, i.e., Anuradhapura, Vauniya, and Trincomalee located in the surrounding HDS, have been considered.

\section{Agricultural Seasons}

There are two main seasons, i.e., Yala and Maha, cultivated by mainly rain-fed small or water provided by larger tanks and sometimes small-scale wells in the NCP. The village tank system, which is also called the 'cascade system', is the major system of the ancient hydraulic civilization in the ancient period. The major cultivation season, Maha begins by October (perhaps late September) and ends by March; it gets higher rainfall from the Northeast monsoon as well as a higher evaporation rate due to warm and withering winds. Paddy is the major crop cultivated during the Maha season while minor during the Yala season (which starts by April mostly end of March to September) due to inadequate water availability. Most farmers cultivate Maha season with adequate rain-fed water and irrigation water, and sometimes they cultivate Yala season with crops, which require less water.

\section{Rainfall and temperature variability}

Long-term rainfall variability and temperature of the area (Horowpathana DS) are analyzed by using the available data of 30 years period starting from 1985 from the three nearest weather stations, i.e., Anuradhapura, Vauniya, and Trincomalee, which are triangularly located in the area. The curve estimation of Regression analysis was calculated and displayed in the following diagrams (See; Fig; 02). Average Annual Rainfall (AAR) at Anuradhapura shows a significant positive trend during the three decades. In Yala and Maha seasons also show a positive trend, but the Maha season

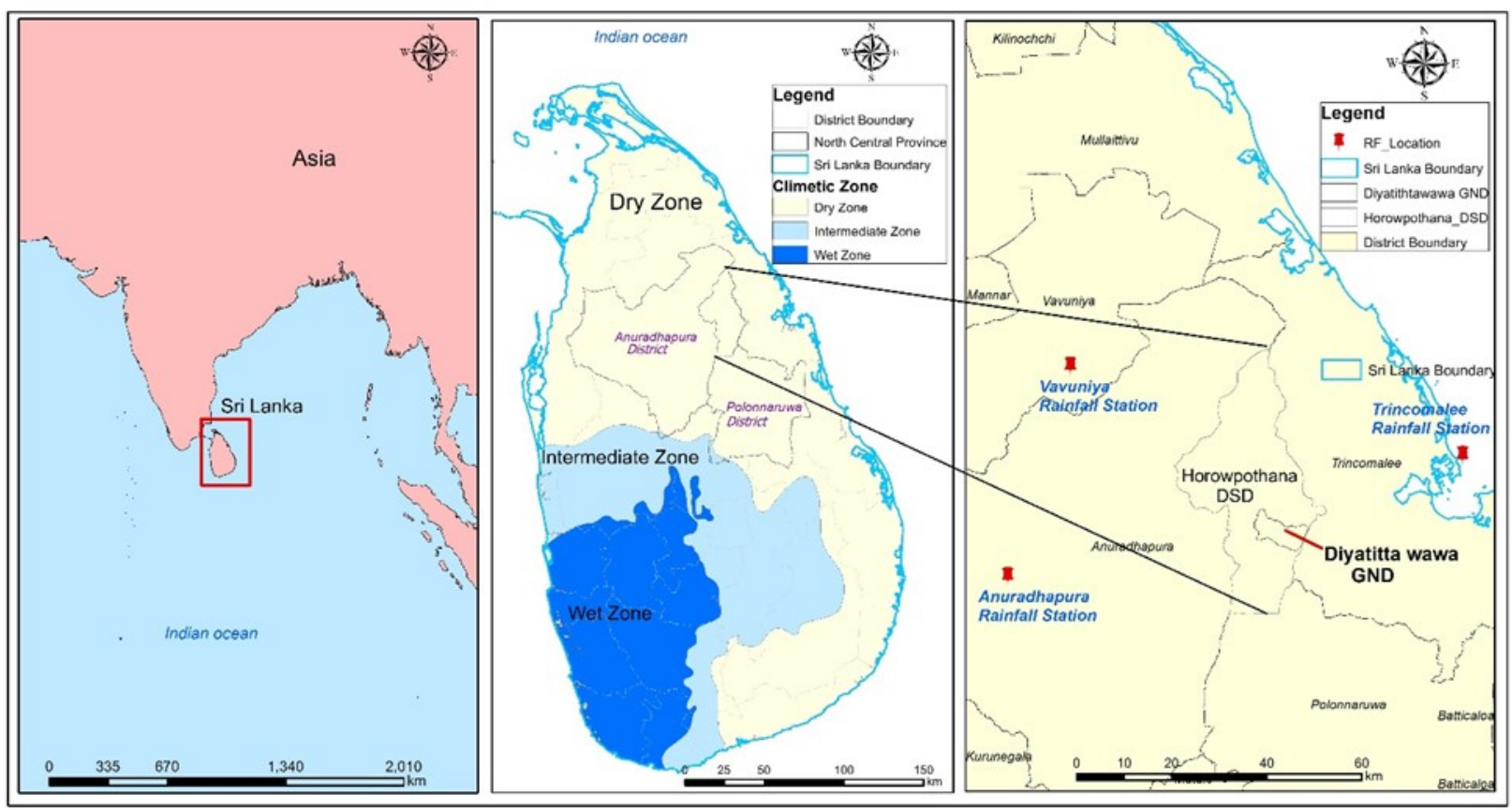

Figure 1. Map of Study area Horowpathana DS and Rainfall stations 
indicates a significant positive trend than the Yala season. It reveals that the rainfall of Anuradhapura has been increasing continuously.

The second weather station, Vauniya is also showing a similar positive trend in rainfall during the period. However, Trincomalee's third weather station is showing a negative trend in AAR during the long-term period. However, rainfall in the Maha season is showing a little positive trend compared to the Yala season. Another interesting feature of the rainfall variability could be identified by analyzing the temporal pattern of the rainfall at the three weather stations. Figure 3 shows the Average Monthly Rainfall (AMR) of the 30 years at the Anuradhapura, Vauniya, and Trincomalee weather stations. Three lines were drawn on each graph indicating the decade of the AMR, i.e., 1985-1994 (green line), 1995-2004 (red line), and 2005-2014 (black line). Thus, three graphs show the unequal pattern of rainfall distribution of the area. Anuradhapura does not show a larger deviation during consecutive periods, but it has recently increased significantly. The Vauniya has been showing clearly the increasing trend of rainfall during all three consecutive periods. However, at Trincomalee, the monthly rainfall pattern has been increasing significantly during the 20052014 period. In general, it could be identified that all the weather stations have been showing increasing trends in monthly rainfall during the period of 2005-2014.

It is possible to identify the temporal pattern of rainfall variability at the study area based on the three weather stations (Figure 4). The maps show the average annual rainfall distribution pattern that has been significantly increasing from the first period (1995-1994) with 96-112mm average rainfall to the third period (1995-2004) at 128$144 \mathrm{~mm}$. The first map shows the AAR is less than $112 \mathrm{~mm}$ through the whole HDS, but it has been changing in the second consecutive period. The second map shows that the eastern part had been getting higher AAR than the western part of the HDS. The third map has clearly shown the rainfall that had been increasing significantly during the period, which indicates climate change of the HDS.

Temperature is one of the primary factors affecting the plant growing, maturing, flowering, and a better harvest. Some studies have proven that warmer temperatures

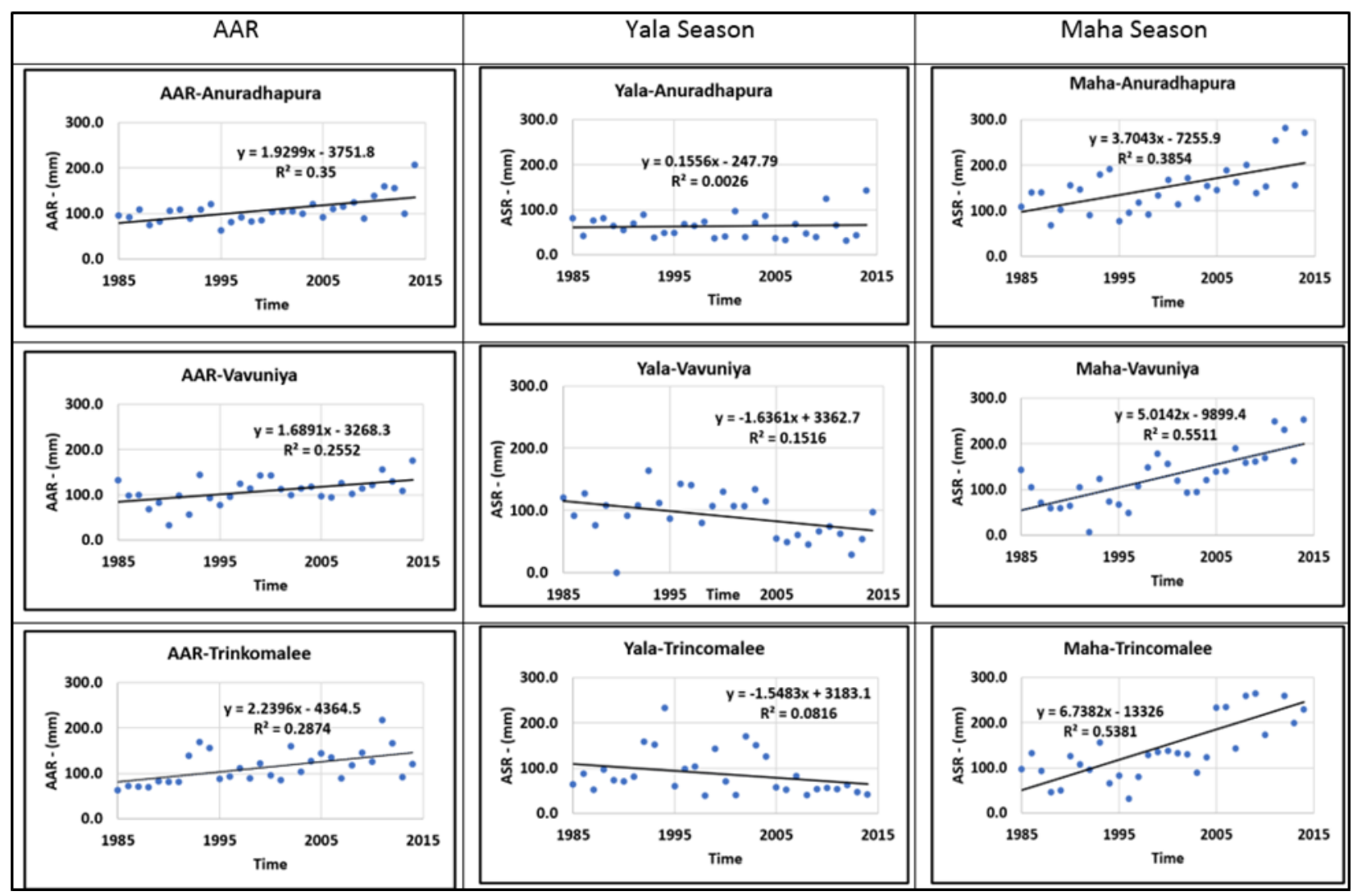

Figure 2. Rainfall variability
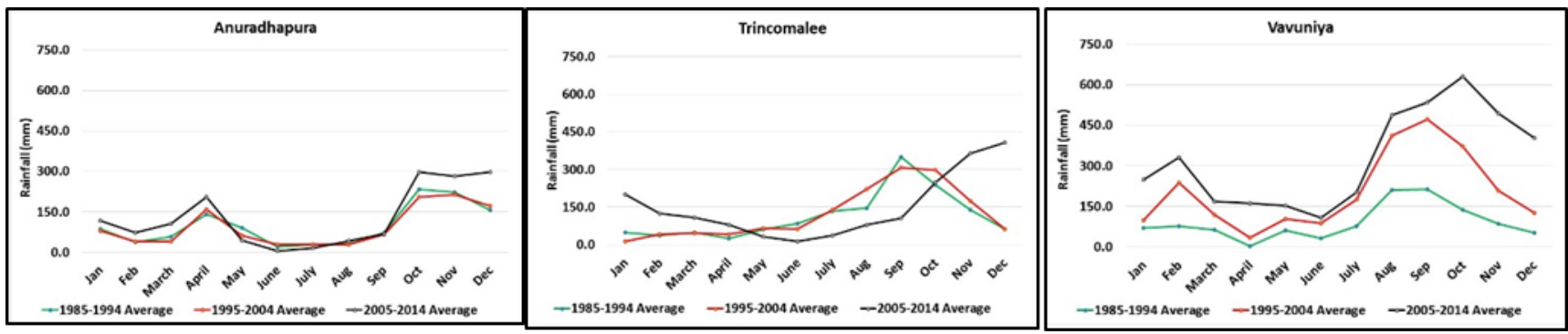

Figure 3. Monthly Average Rainfall Variability 

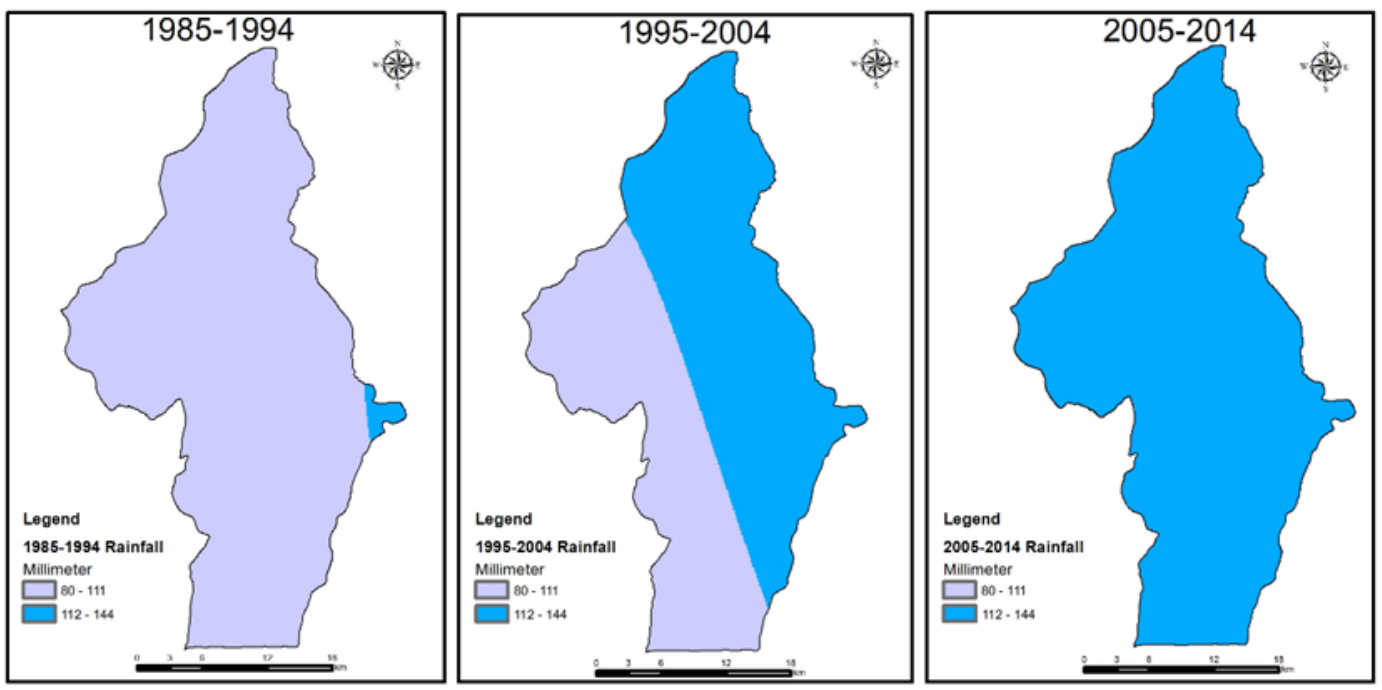

Figure 4. Temporal Distribution Pattern of Rainfall at the HDS

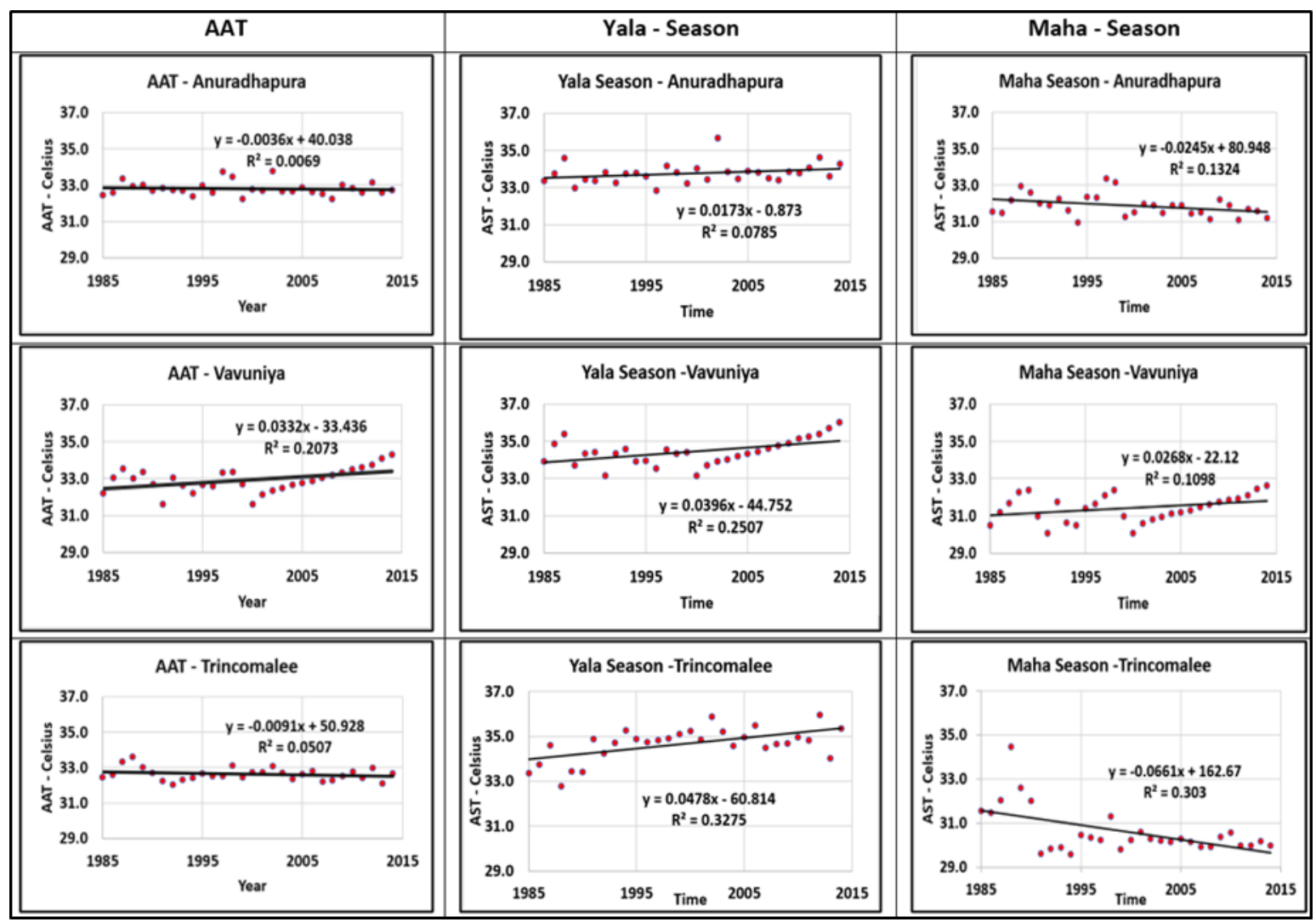

Figure 5. Temperature Variability

expected with climate change and the potential for more extreme temperature events will influence plant productivity. Long-term Average Annual Temperature (AAT) can also be used to identify climate change in the study area. Figure 5 shows the curve estimation of regression analysis of the three weather stations of the area. The long-term trend of AAT and seasonal trend in Maha of Anuradhapura weather station show a slight negative slope while in Yala, slight positive slope curve. The temperature pattern of Anuradhapura is different from the other two stations because of the locational factor. Anuradhapura is located in the middle part of the dry zone of the country. Statistically significant long-term increasing trends for AAT have been shown in both seasons of Vauniya and Trincomalee. The AAT of Vauniya has been showing a significant increasing trend while Anuradhapura and Trincomalee are not. It is also significant that the AAT of Vauniya had been increasing remarkably since 2000 years. Temperature continuously increases significantly at Vauniya. It was clear that the temperature of Vauniya has been increasing promptly since 2000 .

Temperature variability could also be identified by analyzing the temporal pattern of the temperature of the three stations. Figure 6 shows the Average Monthly Temperature (MAT) of the 30 years. The yellow color line of the graph represents the 1985-1994 period, while the red line for 2005-2014 and the black line for the 2005-2014 periods. Three graphs show the temperature has been offering an increasing trend in the first three/ four months of the year 
and then exist at a higher level $\left(33-35 \mathrm{C}^{0}\right)$ till September. The graph further shows that the average temperature is high in both cultivation seasons in the study area. A study by Krishnan et al. (2011) found that an increase in mean temperature or episodes of high temperatures during sensitive stages may reduce rice yields drastically. Accordingly, the two agricultural seasons could be identified as sensitive stages/ periods that may also adversely affect the agricultural production of the study area.

It is necessary to identify the variation of rainfall and temperature with respect to the agricultural seasons to understand the climate change at the study area since the three stations located within a $100 \mathrm{~km}$ radius from the study area do not show an equal pattern of neither rainfall nor temperature perception.

Figures 3 and 6 expose an inverse relationship between AAR and AAT of the three weather stations during the three decades of the period. However, it is significant that both variables of rainfall and temperature increase at Anuradhapura and Vauniya. At Trincomalee, rainfall increases while temperature decreases during the period. There is no significant increase in rainfall at Anuradhapura and Vauniya but temperature increases in the Yala season.

Figure 7 shows the changing spatial pattern of temperature at the HDS. Three maps have been drowned with ranges of $0.15{ }^{\circ} \mathrm{C}$, and the first and second maps do not show any differences in average temperature $\left(32.69-32.84 \mathrm{C}^{0}\right)$ during the two decades. Significantly, the temperature has been increasing in the study area during the last decade starting from 2005 to 2014. The northwestern part of the third map of figure 08 recorded the highest average temperature in between $33.0-33.04{ }^{\circ} \mathrm{C}$. The dark-colored area of the third map reported the highest average temperature $\left(33.00-33.14{ }^{\circ} \mathrm{C}\right)$, and the middle area reported $33.85-33.99 \mathrm{C}^{0}$, which are higher than $0.15-0.30{ }^{\circ} \mathrm{C}$. By analyzing the temperature of the area, it could be summarized that the climate has been changing

\section{Some important socio-economic features of the Study} area (Diya Titta Wewa - DTW)

Some of the vital characteristics summarized here (at the DTW Grama Niladhari Division and the HDS in the NCP) for understanding the spatial pattern of the socio-economic environment. The Village of DTW spread over 50.08 square $\mathrm{km}$, which comprised 182 household units with 892 people. The population structure of the DTW was 50.7, and $49.3 \%$ were male and female of the DTW, respectively. According to demographic data in 2017, one-fourth $(1 / 4)$ of the people who live at DTW were Muslims. It was another significant fact that nearly $76 \%$ of the total number of households consists of more than three family members. The Muslim community has, on average, a higher number of the family than the Sinhala community in the area.

The terrain of the DTW changes from flat to slightly undulating from West to East direction. The terrain condition, groundwater availability, and rainfall are the major factors for supplying water for crop production. The dominant soil types at the DTW village are Reddish Brown

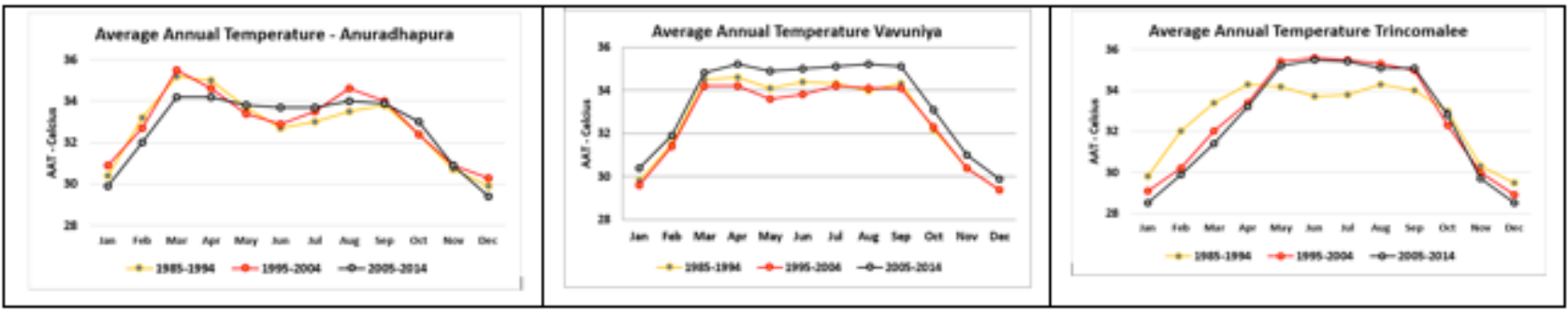

Figure 6. Monthly Average Temperature Variability
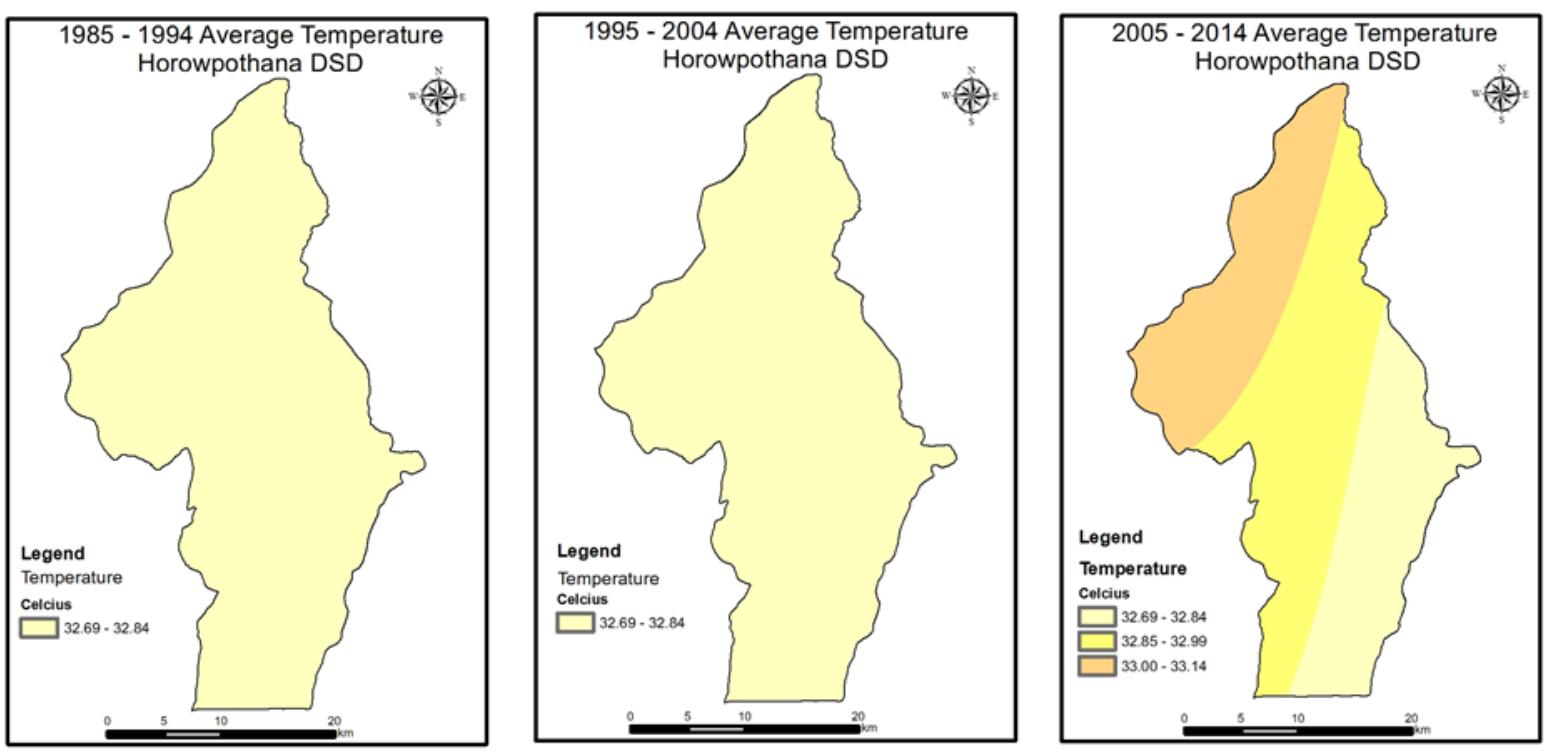

Figure 7. Temporal Distribution Pattern of Temperature at the HDS 
Earth (RBE) and Low Humic Gley (LHG) soils. Consequently, their farming system is totally based on natural phenomena such as rainfall, temperature, humidity, and soil condition. The risk of farming is higher due to the factors such as rainfall instability, drought occurrence, pests and diseases, and damages from wild animals.

A four-fold farming system was evolved at the DTW, i.e., rain-fed cultivation, lowland paddy cultivation in rainfall and tank water and homestead (dwelling gardens), and animal husbandry. The majority of the people in both communities at DTW depend on farming activities, which minor irrigation schemes and rainfall have operated. About 600 hectares of land are being cultivated by a minor irrigation system, while another 85 hectares of land cultivated by rain-fed farming in the village. Farmers cultivate paddy in the Maha season with the onset of Northeast monsoon (November to February) and available water from the tanks.

Several tanks, in different scales, persist in the village. Its scales vary from 25 square feet- s.q. (30,837 cubic metersc.m.) to a maximum of 150 s.q. ( 185,023 c.m.). Local names of the tanks in the area are Seraneewa Wewa, Kuda Seraneewa Wewa, Berawayagama Wewa, Walaha Vidda Wewa, Anaolondawa Wewa and Thibiri Wewa. These tanks were built by constructing earthen dams, and rainwater is collected into the tanks. The water of the tanks fed paddy fields, which are located below the tank. During the Yala season (May to September), where the rainfall is lower than the other site, the farmers mostly cultivated cash crops such as green grams, cowpea, chillies, B-onion and corn.

\section{Climate change impacts and transformational adaptation at the DTW}

Information on perceptions of climate change and its impacts on villagers of the DTW was collected through the survey. Some important features have been discussed here;

a. Knowledge and perceptions on climate change; The respondents of this study showed that all of them were aware of climate change. Responding to the question of 'how do you identify climate change?' revealed that $80 \%$ felt that the weather pattern such as rainfall and temperature was changing 'significantly', and the rest felt that the weather pattern was just changing. All respondents thus felt that there was a change in the general weather patterns.

b. An increase in ambient temperature resulting in more heat stress; All the respondents of the DTW reveal that the temperature has been increasing, and they continuously feel heat stress for the last decades. Further, sixty \% of respondents disclosed that the temperature was unexpectedly high during the last decade compared to previous years. About $30 \%$ of respondents mentioned that a member or more than a family member has been experiencing skin rashes due to the heat condition from March to May period.

c. Frequent and severe occurrence of extreme rainfall anomalies; Most of the respondents disclosed that they have been confronting extreme weather conditions such as flood and drought. The drought has been happening continuously since 2016, but the number of affected people is gradually reducing. Agricultural failures due to either flood or drought subsequently affect village economy, livelihood, and employment opportunities, resulting in financial hardship. Table 1 shows the severe occurrence of floods and drought during the last decade in the area. It shows that at least half of the villagers were adversely affected by either flood or drought in the year-the highest number of families and people affected by drought in 2017 at the DTW.

d. Increasing trend of natural calamities; When examining the impact of natural calamities, the study identified that beyond production losses, medium and large-scale calamities could have a significant impact from growth to yield, with negative consequences on agricultural production. The Gantt chart (Table 2) shows the generalized temporal pattern of natural calamities happening in the study area. According to the chart, the months of March to April and October to November could be identified as the high vulnerable period for natural calamities. It is observed that natural calamities are significant and continuous every year for the last couple of years. Apart from floods, strong winds/ cyclones, thundering/ lightning, and droughts, farmers have been experiencing wild elephant attacks on their cultivation, resulting in loss of their yield.

Extreme weather conditions strongly affect crop yield; drought is a major reason for soil dryness in fields, and floods usually bring excessive soil water; both of them severely restrict crop growth, germination, and yields. Any extreme weather condition has a great impact on agriculture and its production. All the respondents of this study have disclosed that the drought and flood had caused a significant decrease in the crop's production with serious villagers' livelihood issues.

This study has identified several transformational adaptation strategies to overcome these problems in the study area. Major findings of adaptation strategies are as

Table 1. Natural hazards occurred in the study area

\begin{tabular}{llcc}
\hline Year & Types of Hazard & Number of affected families & Number of affected people \\
\hline 2011 & Flood & 180 & 690 \\
2014 & Flood & 195 & 720 \\
2016 & Drought & 210 & 875 \\
2017 & Drought & 283 & 883 \\
2018 & Drought & 100 & 430 \\
2019 & Drought & 75 & 300 \\
\hline
\end{tabular}

Source: Field survey (2020) 
follow;

a. Transforming agricultural activities from intensification to more intensification, gross per capita land availability at the DTW is about 5.5 hectares, but most land cannot be cultivated due to water scarcity and wild elephants occupying nearby forests. Agricultural practice of the DTW could be identified as small-scale commercial farming, and this type of farming is usually characterized by intensive cultivation practices adopted by the Green revolution, intensive use of labor, and in most cases, surplus production sold to the local or surrounding markets. However, climate change has been paralyzing the agricultural system in the village. Farmers have been transforming their farming methods, which match the climatic condition by adopting more intensification methods to achieve better yield with the limited cultivable land. Selecting seeds, use of agrochemicals, weeding, and use of machines are the components of intensification. Farmers have already dug 18 agro-wells to continue the supply of water for their cultivation. This system is leading to 'Climate Smart Agriculture - CSA,' which integrates and systematically intensifies farm activities to meet climate change. The CSA provides the foundations for incentivizing and enabling intensification to improve risk management (Bruce et al.,2014; Campbell et al., 2014).

b. Crop diversification; refers to cultivating more than one variety of crops in different species in an area in the form of rotations and or intercropping is called crop diversification; more specifically, it could be identified as horizontal crop diversification (see; Dharmasiri, 2013). About $60-70 \%$ of the farmers at the DTW practice crop diversification to minimize risk and uncertainty from farm production as another adaptive strategy to climate change. They cultivate paddy and cash crops together in one land in the Maha season and several cash crops in the Yala season in a land. A study was done by Malicki et al., 2012 found that the Sahelian farmers also tend to diversify their activities to reduce their vulnerability to external shocks. Their activities are similar to the Sri Lankan scenario.

c. Out-migration from rural to the urban sector; A contemporary trend is that the rural youth and some frustrated farmers have been migrating to urban sectors seeking employment opportunities to overcome their financial difficulties due to crop failure. In particular, some youth belonging to the Muslim community have been migrating as agricultural laborers in the Eastern part of the country, where the Muslim community is dominant and cultivates paddy under irrigation facilities. It is a common phenomenon to migrate people to avoid adverse situations in most developing nations. One of the best examples provided by the Touguo people (Sahelian, Burkina Faso), which have already migrated one-third from the North to the South over the last few decades due to climate conditions (Malicki et al., 2012).

d. Adaptation of drought tolerance crops; Even though the farmers are unwilling to change paddy cultivation in the Maha season in the DTW due to climate change, the sector is heavily subsidized by the Government. Under the circumstance, the farmers have been adaptative, transforming into new varieties of paddy such as BG250, BG-300, BG 10-9024, and BG 10-9028, which have a shorter duration and tolerate drought conditions. In the Yala season, where the water scarcity is high, farmers cultivate cash crops such as soya beans, onion, and chilies, which can tolerate drought to a certain extent under the tanks and agro-wells.

e. Transforming from agriculture to animal husbandry; Some people who evicted from agriculture have been rearing cattle, buffalo, and goats at the DTW on a different scale. It varied from 2 to 20 of a herd. They rear animals for milk and sell for slaughter, resulting in better income. Barren land, abundant paddy fields, and nearby jungle are the places where they fed animals.

f. Households keep several small-scale poultry farms (family farms) at the DTW. About $70 \%$ of households of the village have local chickens and manage by locally available feedings. The poultry size depends on the land size where their house is located and mainly keeps the women's activity. The activity helps to find their own food and additional income generation for the families. Even though the family farm system is not a new phenomenon, women of the village do practice survival of livelihood, a strategic aspect of adaptation to climate change.

\section{Conclusion}

Climate change, impacts on climate change, climate change adaptation, and farmer adaptation to climate change at the micro-level situation have been examined in this study. The agricultural sector could be identified as the most vulnerable sector to climate change, and farmers have been struggling to cope with the adverse impacts. The study has identified several climate change impacts, i.e., All the people in the village have better knowledge and perceptions on climate change, they feel that the ambient temperature has been increasing and resulting in more heat stress, the frequent and severe occurrence of extreme rainfall anomalies and increasing trend of natural calamities. The farmers of the area have been adopting several strategies to overcome the negative impacts of climate change.

The study found that transformational adaptation strategies are vital and required meeting the unforeseen future, on adverse impacts on climate change at micro and macro levels. It was evident that the agricultural activities have been transforming from intensification to more intensification that can be identified as Climate Smart Agriculture (CSA) which would be an ideal strategy to minimize adverse impacts on the present scenario. In addition, crop diversification and adaptation of drought tolerance crops are also important aspects for the mitigation of negative aspects of climate change. Transforming from agriculture to animal husbandry is another important strategy that could be further enhanced by providing microfinanced to the target groups. Out-migration of unemployed or evicted youth from agriculture to non-agriculture (rural to the urban sector) would be able to earn wages and improve their living standards of life while providing labor requirements of the urban sector. Institutional involvement is essential to strengthening the adaptative strategies of the people by providing an appropriate crop calendar and most suitable crop combination for maximizing the yield while minimizing the risk and aware of the way of improving the use of the efficiency of available water for improving the living standard of the people. 


\section{References}

Adhikari A, Shah R, Baral S, Khanal R. (2011). Terminologies Used in Climate Change. $124 \mathrm{p}$.

Battisti DS, Naylor RL. (2009). Historical warnings of future food insecurity with unprecedented seasonal heat. Science (80). 323(5911):240-4.

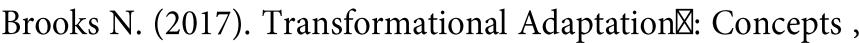
Examples, and their Relevance to Agriculture in Eastern and Southern Africa.

Bruce CM, Thornton P, Zougmore R, Asten PV and Lippe L (2014). Sustainable intensification: What is its role in climate smart agriculture?. Available from: DOI: 10.1016/ j.cosust.2014.07.002

Chithranayana RD, Punyawardena BVR. (2014).Adaptation to the vulnerability of paddy cultivation to climate change based on seasonal rainfall characteristics. J Natl Sci Found Sri Lanka.;42(2):119-27.

De Costa WAJM. (2008). Climate change in Sri Lanka: Myth or reality? Evidence from long-term meteorological data. J Natl Sci Found Sri Lanka.;36(Special Issue):63-88.

De Silva CS, Weatherhead EK, Knox JW and Rodriguez-Diaz J A, (2007). Predicting the impacts of climate change - A case study of paddy irrigation water requirements in Sri Lanka. Agricultural Water Management, 93. 19-29. DOI: http://dx.doi.org/10.1016/j.agwat.2007.06.003.

Dempewolf H, Eastwood RJ, Guarino L, Khoury CK, Müller J V., Toll J.(2014). Adapting Agriculture to Climate Change: A Global Initiative to Collect, Conserve, and Use Crop Wild Relatives. Agroecol Sustain Food Syst.;38 (4):369-77.

Dharmasiri, RKLM, (2013). Crop Diversification for Sustainable Agriculture: A Case Study from the Mahlaweli Development Hector Kobbekaduwa Agrarian Research and Training Institute. Colombo; 12 (01): 53-68

Esham M, Garforth C. (2013).Climate change and agricultural adaptation in Sri Lanka: A review. Clim Dev.;5(1):66-76.

Fernando TK, (2000). Impact of climate change on paddy production in Sri Lanka. Global Environmental Research, 2. $169-176$

Gori A, Brito CB and Ruiz J, (2018). Climate change and agriculture: Do environmental preservation and ecosystem services matter?, Ecol. Econ. 52:27-39. Retrieved from https://doi.org/10.1016/j.ecolecon.

Guarino L, Lobell DB. (2011). A walk on the wild side. Nat Clim Chang [Internet].;1(8):374-5. Available from: http://dx.doi.org/10.1038/nclimate1272

Gunasena HPM, Gunathilake HAJ, Everard JMDT, Ranasinghe CS, and Nainanayake AD, Proceedings of the International Conference on Climate Change Impacts and Adaptation.

https://www.researchgate.net/ publication/344249915_Impact_of_Climate_Change_Aw areness on Climate Change Adaptions and Climate Change Adaptation_Issues

Gunawardhana AP and Dharmasiri LM, (2015). Drought and Adaptation Strategies of the People in the North Central Province of Sri Lanka.

https://www.researchgate.net/ publication/344249915_Impact_of_Climate_Change_Aw areness on Climate Change Adaptions and Climate Change_Adaptation_Issues

IPCC. Climate Change (2001). Synthesis Report. IPCC Third
Assessment Report (TAR). Ipcc [Internet]. 2001;409. Available from: http://www.ipcc.ch/ipccreports/tar/

Jayawardene H, Sonnadara D, Jayewardene D. (2005). Trends of Rainfall in Sri Lanka over the Last Century. Sri Lankan J Phys.;6(0):7.

Krishnan P, Ramakrishnan B, Reddy KR, Reddy VR. (2011). High-Temperature Effects on Rice Growth, Yield, and Grain Quality [Internet]. 1st ed. Vol. 111, Advances in Agronomy. Elsevier Inc.;. 87-206 p. Available from: http://dx.doi.org/10.1016/B978-0-12-387689-8.00004-7

Lemos MC, and Hulme M, (Ed.) (2018). Transformational adaptation of agricultural systems to climate change. Retrieved from: https://doi.org/10.1002/wcc.520

Malicki Zorom, Bruno Barbier, Ole Mertz and Eric Servat, (2013). Diversification and adaptation strategies to climate variability: A farm typology for the Sahel., Agricultural Systems 116:7-15, DOI: 10.1016/ j.agsy.2012.11.004

Marambe B, Pushpakumara G, Weerahewa J, Punyawardane (2013). Climate change and household food security in homegardens of Sri Lanka. Proc Int Conf Clim Chang Impacts Adapt Food Environ Secur.;(DECEMBER):87100.

Menike LMCS, and Arachchi KAGPK, (2016). Adaptation to Climate Change by Smallholder Farmers in Rural Communities: Evidence from Sri Lanka, Procedia Food Science, Volume 6, 2016, Pages 288-292, ISSN 2211601X, https://doi.org/10.1016/j.profoo.2016.02.057

Ministry of Mahaweli Development and Environment. (2016). Climate Change Secretariat, Ministry of Mahaweli Development and Environment [Internet]. Available from:

https://www4.unfccc.int/sites/NAPC/Documents NAP/ National Reports/National Adaptation Plan of Sri Lanka.pdf

Moser SC, Ekstrom JA. (2010). A framework to diagnose barriers to climate change adaptation. Proc Natl Acad Sci U S A.;107(51):22026-31.

Noman and Schmitz (2011). Impact of Climate Change Awareness on Climate Change Adaptions and Climate Change Adaptation Issues,

https://www.researchgate.net/ publication/344249915 Impact of Climate Change Aw areness_on_Climate_Change_Adaptions_and_Climate_ Change Adaptation Issues

Panabokke CR, Punyawardena BVR. (2010). Climate change and rain-fed agriculture in the dry zone of Sri Lanka. Proc Natl Conf water, food Secur Clim Chang Sri Lanka [Internet];Volume 2:141-6. Available from: http:// www.iwmi.cgiar.org/Publications/Other/PDF/ SLWC Volume-2-Latest.pdf

Rickards L, Howden SM. (2012). Transformational adaptation: Agriculture and climate change. Crop Pasture Sci.;63(3):240-50.

Seo SN, Mendelsohn.( 2008). R. A structural ricardian analysis of climate change impacts and adaptations in African agriculture. World Bank Policy Res Work Pap.;38(4603):151-65.

Sönke K, Eckstein D, Dorsch L, Fischer L. (2020). Global climate risk index 2020 [Internet]. 1-28 p. Available from: https://germanwatch.org/en/download/7170.pdf

Wijeratne MA, (1996). Vulnerability of Sri Lanka tea production to global climate change. Water, Air and Soil 
Pollution, 92. 87-94. DOI: 10.1007/BF00175555

Yilma Z, Haile A, and Bleich EG, (2019). Effects of climate change on livestock production and livelihood of pastoralists in selected pastoral areas of Borana, Ethiopia, Food and Agriculture Organization of the United Nations, Sub Regional Office for Eastern Africa (FAO/ SFE), Addis Ababa, Ethiopia.

Zakeer Ahmed Khan and Allah Nawaz, (2000).Impact of Climate Change Awareness on Climate Change Adaptions and Climate Change Adaptation Issues, Pakistan Journal of Agricultural Research,36(3), DOI: 10.17582/journal.pjar/2020/33.3.619.636 